Physics at the University College of Rhodesia and Nyasaland: Dr. E. Leighton Yates

DR. E. Leighton Y YTES, senior lecturer in physics in the University of Sheffield, has been appointed to the chair of physics in the University College of Rhodesia and Nyasaland, Salisbury, Southern Rhodesia. Educated at the Grove Park Grammar School, Wrexham, he then studied under Prof. E. A. Owen at the University College of North Wales, Bangor, and graduated with first-class honours in physics. He did postgraduate work with Prof. Owen on X-rays, developing a high-temperature camera and investigating pure iron-nickel alloy systems. Proceeding to St. John's College, Cambridge, with a senior research award of the Department of Scientific and Industrial Research, he worked in the Cavendish Laboratory on the separation of the isotopes of lithium, boron and carbon. Dr. Yates is an excellent teacher, having lectured and demonstrated for many years and at all levels to general- and to special-degree students. During the Second World War he was largely responsible for conducting a two-year course at Sheffield in radiophysics and for developing a comprehensive practical course in radio. $\mathrm{He}$ has initiated extra-mural and postgraduate courses in electronics, metal physics and modern physics and given courses in building acoustics. Alone and with his co-workers, he has worked on the development of electronic control devices, the X-ray examination of metals and alloys, order-disorder transformation in $\mathrm{FeNi}_{3}$, the growth of single erystals of iron, their magnetic properties under strain, and the design of an X-ray diffractometer for examining strained crystals, using a fine-focus $X$-ray tube. Dr. Yates's wide knowledge and experience have been always freely available to his colleagues. In the Student Christian Movement, his services have been greatly prized both in the universities and in schools.

\section{Kossuth Prizes for Research in Hungary}

Twe Hungarian Government has awarded a number of Kossuth Prizes for research, as follows. First-class Prizes, of £1,500 each: Academician László Rédei, for work in the field of algebra and theory of numbers, and particularly for his treatise on the Pell type of equations; and Academician Gyözo Bruckner, for research on polypeptides and proteins, significant from the biological point of view. Second-class Prizes, of $£ 1,000$ each : Dr. József Baló and his wife, for research into the pathology of the blood system and the discovery of a new enzyme which digests fibrous tissue; Dr. Yéter Dénes, for an electrolytic method of producing iron and alloy powders used in the telecommunications industry; Academician Séndor Geleji, for research in the plastic moulding of metals: Academician Géza Hetényi, for work on the diagnosis of ulcer diseases; Academician Árpád Kiss, for spectroscopic research on aromatic hydrocarbons and hydrated metal ions and complex salts; and Zoltán Veress, chief engineer of the Karcag factory, for the production of special glasses, $C 9$ and
Q28, for the telecommunications industry.

\section{Scientific Research in the U.S.S.R.}

UNDE.R the title "Scientific Research in Russia", the Depariment of Scientific and Industrial Rosearch has issued a translation of a brief survey of recent work which appeared in Priroda (1954, (3) 3-10). Some initial and final paragraphs, political in character, have been omitted, and in the absence of a biblio- graphy some references have been added to indicate Russian periodicals received in Britain which are likely to deal with the subjects mentioned. There is still a little polemic; but the survey indicates the scope of the Russian effort. Much work has been completed on regional tectonics and the problems of magmatogenic mineral deposits. Stress is laid on investigations relating to the construction of turbo-generators, the discovery of new types of solid fuel for metallurgy, the improvement of special alloys for machine construction, and the automatic control of blast and open-hoarth furnaces. In the petroleum industry use of the turbine method of boring has been extended, and the gasification of coal has been further developed, as well as the catalytic methanization of water gas and the use of steam at high pressures and temperatures. Contributions in radio-astronomy, the physics of semi-conductors, the development of scismological methods and studies of the effect of molecular structure on the rate of isotope exchango and of the mechanism of poly-condensation are noted, as well as the introduction of a new anresthetic, promedol, claimed to be more active and less toxic than morphine. Reference is made to studies of the action of phosphatic fertilizers with radjoactive phosphorus and of the use of antibiotics for the control of plant diseases; but, in general, it is stated that radioactive tracer materials have been used to a very limited extent and that use of the electron mieroscope has been unsatisfactory.

\section{Visual Recording of Radiation Patterns}

SEVERAL different types of apparatus have been devised for the formation of visual images of patterns of ionization; but with the exception of those described by Prof. W. V. Mayneord and co-workers at the Institute of Cancer Research, London, they all present the final picture on recording paper or film. Prof. Mayneord uses the cathode-ray tube, and in earlier models (Nature, 168, 762; 1951; and Brit. J. Radiol, 25, 589; 1952) a persistent screen was employed. However, at low scanning speeds the persistence was found to be insufficient, and in the most recent model, which has recently been described (J. Sci. Instr., 32, 45 ; 1955), an image-storage tube is used in place of the cathode-ray tube. The picture is built up, line by line, over a long period of time,
and then the complete picture is read at any later convenient time. The apparatus consists essentially of two parts: a mechanical device for moving the detector accurately over the required field of examination, and the electronic sections concerned with the detection of the radiation and the ultimate storage and presentation of the final image. The source is scanned in a series of parallel lines, and the maximum area covered can be $18 \times 13 \frac{1}{2}$ in. The time taken for scanning a complete frame is approximately six minutes. As the apparatus described was designed primarily for the survey of radiation fields due to $\gamma$-ray emitting isotopes, the detector is a coincidence scintillation counter; but, by the substitution of other detectors, the use of the apparatus can be extended over a wider range of radiations. Full details of the detector system and of the storage tube are given, and problems of resolution and limits of detection are discussed and illustrated by photographs. A minor modification perrnitting the apparatus to be used for making radiographs is mentioned, and the application of the storage principle to an X-ray spectrograph is stated to be under consideration. 